\title{
Facebook out of control? A technically-mediated autonomous technology $\mathbf{y}^{1}$
}

Amanda Chevtchouk Jurno* (D)

* Universidade Federal de Minas Gerais (UFMG), Belo Horizonte (MG), Brasil. E-mail: amandajurno@gmail.com

Received: i6 October 20 i 8 Revised version: 29 March 2019 Accepted: 22 August 2019.

\section{Abstract}

On the controversy triggered by the influence of the so-called "fake news" that circulated on Facebook in the 2016 United States presidential elections, we notice the emergence of an idea of "control of technology", both in the platform's official publications and steps announced after the event, and in the specialized media demands. In order to refute the idea of total control of technology and defend the recognition of the action of nonhuman elements, thus contributing to a better understanding of the platform's actions, we use the concepts of “autonomous technology", by Langdon Winner (1977), and "technical mediation", by Bruno Latour (1994). Methodologically, we were inspired by the Cartography of Controversies (VENTURINI, 2010) and worked with content collected through the platform's official pages and media vehicles that covered the event from July 2016 to July 2018.

KEYwords | Facebook; Autonomous Technology; Technical Mediation; Algorithms; Platform.

1 Translation by Raisa Mendes, B.A., Social Communications from the Federal University of Minas Gerais (UFMG - Brazil) and Post-Graduate, Public Relations \& Corporate Communications from Centennial College (Canada). 


\section{Introduction}

Throughout 2017, Facebook appeared in the media in a series of attempts to provide clarification and justify itself for the action of its algorithms and tools. Many of the latter, also called "sections" by the company, were the subject of complaints and inquiries, for example, about the possibility of segmentation of sponsored posts to users classified into questionable categories, such as "Jewish haters" (LEVIN, 2017), or the criteria used to determine what would be considered "hate speech" (ANGWIN; GRASSEGGER, 2017) and, therefore, likely to be deleted by the platform. Among the most discussed issues over the period dubbed the "Facebook's hellish two years" by Wired Magazine journalists Nicholas Thompson and Fred Vogelstein (2018), were the controversy surrounding the biased selection of content, the spread of the so-called "fake news" and the platform's attempt to handle this crisis.

Among so many points to be explored in relation to this controversy, in this article we are interested in highlighting and discussing an issue that has appeared frequently throughout the repercussions involving Facebook but is not restricted to the action of this platform. It is related to a recurring idea when discussing the action of technologies which are present in our daily lives and the way this action impairs the analysis and understanding of how these technologies act. We propose then to look at the idea of technical control that emerged in the analyzed period, both in the official speeches of Facebook and in the specialized media, and that was mainly related to the algorithmic selection of content on the platform. We believe that the ideas of technical control and machine neutrality that permeate the publications make it difficult to understand the participation of the platform and its elements in the users' construction of meaning. This simplistic view, especially in relation to algorithms, also hinders the understanding of platforms as sociotechnical networks composed of various human and nonhuman actors - networks in which it is impossible to determine the origin of the action.

To provide a critical look at these actors and their actions we rely on two leading authors from the Science and Technology Studies (STS) field of knowledge. Although not directly related, we believe that Winner's (1977) "autonomous technology" and Latour's (1994) "technical mediation" are concepts which can be used together to think about this particular issue. Our intention here is to demystify the idea that humans would be able to completely control technology and to move away from a perspective that associates this technology with the idea of object neutrality, in which humans would override techniques (technical means). In contrast, we propose 
to focus our energies on figuring out "when" action occurs and how to prevent it from recurring so that legally liable persons can take appropriate action, instead of an eternal search for those directly responsible, as Bucher recommends (BUCHER apud D'ANDRÉA; JURNO, 2018). When we look for those who are directly responsible for an action - which is theoretically impossible to determine, as we will argue ahead -, solutions and improvements are left behind or even forgotten.

Therefore, we seek to understand the relationship between media and technology as a complex and sociomaterial phenomenon as opposed to a technologicaldeterministic view of content. We follow the proposition of Gillespie, Boczkowski and Foot (2014) to think about the ways in which materiality, practice and politics are interconnected, debating material ramifications without exaggerated simplifications, and postulating these sociotechnical interconnections as situated historically and in specific sociopolitical contexts. From a methodological point of view, we seek inspiration from the Cartography of Controversies (VENTURINI, 2010) to map and identify the human and nonhuman actors linked to this controversy. Our corpus analysis is based on the company's official publications from July 2016 to July 2018 - both on executives' personal profiles, the company's websites and the Newsroom blog (NEWSROOM, 2019) -, in the specialized media outlets that covered the topic, and in professional opinion articles on the subject. Due to the structural impossibility of presenting the complete controversy in this article, ${ }^{2}$ we will show some quotes that exemplify the emergence of these technical control ideas during the controversy and that help us draw the panorama that has been formed around the subject in the last two years.

In the following topics, we briefly present the two concepts that guide us in the analysis; we draw an outline of the controversy and its main actors and events; we analyze critically some of the quotes selected to exemplify the speech that emerged from the controversy; and we conclude with our understanding of the issue.

\section{Control? Autonomy and agency of nonhumans}

In order to reflect on the action of Facebook in the users' construction of meaning and the broader sociotechnical networks of which it is a part, we need to take a critical view of the actions of its constituent elements instead of treating them as neutral intermediaries or agents who are under complete control of their human colleagues.

2 This work is part of a broader research, linked to the PhD Dissertation in development by the author in the Communication Graduate Program of the Federal University of Minas Gerais (UFMG), Brazil. 
Thus, we suggest using the concepts of autonomous technology (WINNER, 1977) and technical mediation (LATOUR, 1994) to observe this phenomenon with a more critical and less simplistic look. Although they are presented by authors with very different theoretical perspectives, we believe that both concepts can be used complementarily and help us think, in a broad way, about the action of Facebook and its algorithms in these sociotechnical networks.

Langdon Winner is a political theorist who studies "how technological development involves the restructuring of the forms of everyday activity" (WINNER, 1983, p. 253) and how technologies incorporate forms of power. For the author, attention must be paid to society's response to certain technological imperatives, offering other ways of interpreting and explaining the agency of technological artifacts, seeing them as important in social processes (WINNER, 1983.

For Winner (1977, p. 19), "the conclusion that something is 'out of control' is interesting to us only insofar as we expect that it ought to be in control in the first place". For him, the idea that technology is somehow "out of control" is political in nature and rooted in anthropocentric conceptions of power and domination of society. In his works, the author warns about the problems associated with this imagery of techniques as "master-slave", trying to demystify this traditional way of thinking about technology as being under absolute control of its human creators.

Like his colleagues in STS, Winner argues that technologies are part of large and complex networks, over which neither humans nor technologies have complete control because these networks are the result of the actions of the various elements that compose them. Moreover, the author believes that technological development is concomitant with social development, corroborating the STS central idea that technology and society cannot be considered separately.

In this paper, we argue that the concept of autonomous technology (WINNER, 1977, p. 16), seen as "a general label for all conceptions and observations to the effect that technology is somehow out of control by human agency", can be very helpful to think about the controversy that has unleashed around Facebook and the allusion to content control on the platform - either by the company or by the external demands that circulated in the news media.

\subsection{Winner and autonomous technology}

Winner (1977) believes that technological development generates a growing increase in social complexity, requiring a continuous adaptation of the elements that are 
in contact with these technologies. As technology, in its various manifestations, is a significant part of the human world, "its structures, processes and alterations enter into and become part of the structures, processes, and alterations of human consciousness, society and politics" (WINNER, 1977, p. 6). According to him, as these technologies advance and become more complex, it is becoming increasingly easy to see how they are not completely under human control and how it would be impossible to predict all their effects, whether positive or negative. This way, "far from being controlled by the desire and rational ends of human beings, technology in a real sense now governs its own course, speed, and destination" (WINNER, 1977, p. 16).

Sometimes criticized as a deterministic theorist, Winner responds to his critics by saying that humans do have choices in the face of technological change, but these singular choices cannot change the overall picture, nor discover the whole process to which it refers. He prefers then to see humans as in a state of "technological somnambulism - how we, so willingly, sleepwalk through the process of reconstituting the conditions of human existence" (WINNER, 1983, p. 254).

The author emphasizes the need to get out of this state of daze by studying the political consequences of technological choices and how they transform our personal experience and social relationships. For him, we should do it thinking

[...] about technological design features in roughly the same way that the legislators of the ancient world or the eighteenth-century philosophers pondered the structural characteristics of political constitutions. Technologies provide frameworks of order for the modern world. As such, it now makes sense to try to understand the forms of authority, justice, public good, and freedom that their order entails. (WINNER, 1983, p. 262)

From a different perspective, but also related to STS and its guiding concepts, Bruno Latour (1992) argues that technological progress does not eliminate humans, but instead mobilizes more and more people.

Indirectly criticizing Winner's perspective, he claims that "the 'autonomous' thrust of a technical artifact is a worn-out commonplace made up by bleedingheart moralists who have never noticed the throngs of humans necessary to keep a machine alive" (LATOUR, 1992, p. 251-252).

In turn, Winner criticizes Latour, and his theoretical colleagues of the ActorNetwork Theory (ANT) and the so-called social constructivism, as apolitical 
researchers. Winner (1993) considers the study of the origins of technology to be misleading, rather than the consequences of these technological choices, as if these consequences, effects or impacts had already been widely studied (p. 368). And, says Winner (1993, p. 372), based on the premise of methodological purity adopted by these researchers, it is likely that they "will continue their research without taking a stand on the larger questions about technology and the human condition that matter most in modern history".

It is exactly based on the criticism of ANT research that we believe that the combination of the two aforementioned concepts can provide us with a richer analytical tool. Furthermore, both authors argue that technical artifacts are part of large and complex sociotechnical networks, composed of interconnections and systemic interdependence, so large that none of their elements is able to maintain control of the whole. Both criticize the idea that "we can master techniques, that techniques are nothing more than pliable and diligent slaves" (LATOUR, 1994, p. 31) and that is precisely the idea that we intend to discuss in this paper, bringing the example of Facebook.

\subsection{Latour and technical mediation}

Bruno Latour is a critical theorist of traditional sociological approaches in which, according to him, the word "social" is used as an explanatory adjective, losing its original meaning and diverting efforts from what should be the object of study - the social itself (LATOUR, 2005). Moreover, Latour advocates the end of dualisms and the idea of purification, which he calls the "illusions of modernity" (LATOUR, 1994), for the legitimation of hybrids - associations between humans and nonhumans.

Before we get to the concept that interests us in this paper, we need to explain that, for this author, "no unmediated action is possible" and "action is a property of associated entities" (LATOUR, 1994, p. 29, 35). Therefore, "responsibility for action must be shared among the various actants" (LATOUR, 1994, p. 34) existing in a network of actors. For him, to "act" is to make someone or something act, to put in contact two elements for a possible relationship: "Essence is existence and existence is action" (LATOUR, 1994, p. 33).

Latour proposes the concept of technical mediation to question the myths of the "neutral tool" or of the "autonomous destiny" and argues that in a man-object association both agents modify their actions symmetrically and it is impossible to think about the action of the parts separately. To explain the concept, he offers 
some meanings and significance, among them the "action program": a series of steps and intentions described in a situation that can also be called "translation". 3 Translation is the creation of a link from the association of certain actors that did not exist before and that modifies the elements in association. That is why the author considers action to be the property of associated entities - human and nonhuman - in which the principle of symmetry should prevail, replacing the subject-object dichotomy. Symmetry in action must be thought of both as we look at the process of creation of technical objects as well as their action in a network.

According to Latour, the difficulty in measuring the role of technical mediation with any precision lies in the fact that "the action that we are trying to measure is subject to 'blackboxing,' a process that makes the joint production of actors and artifacts entirely opaque" (LATOUR, 1994, p. 36), i.e., it was transformed into a black box whose inside it is not possible to know. "Blackboxing" is the process that makes an agency between subject-objects opaque and almost invisible, and makes us see only the result of the actions of these black boxes, without visualizing all the actions that are needed. This "blackboxing" of programs of actions allows the displacement of the actants' timeline and a detour in the sequence of actions in another network.

Detour, translation, delegation, inscription, and displacement require our better comprehension before we can even begin to elaborate a philosophy of techniques; and understanding these requires that we understand what semioticians call shifting. (...) I transport you not only into another space and time but translate you into another actor. I shift you out of the scene you presently occupy. (LATOUR, 1994, p. 39)

This way, Latour (1994, p. 40) recommends that we "think of technology as congealed labor" and that this ordering of presence and absence is redistributed throughout the networks of actors, making it possible to displace and find hundreds, even thousands, of missing creators - remote in time and space and simultaneously active and present in the actions performed. And so, he believes that the political order is subverted through such detours, as we are constantly relying on "delegated actions that themselves make me do things on behalf of others who are no longer here and that I have not elected and the course of whose existence I cannot even retrace" (LATOUR, 1994, p. 40).

3 "Translation does not mean a shift from one vocabulary to another, from one French word to one English word, for instance, as if the two languages existed independently. Like Michel Serres, I use translation to mean displacement, drift, invention, mediation, the creation of a link that did not exist before and that to some degree modifies two elements or agents" (LATOUR, 1994, p. 32). 
Bruno Latour also argues that the word "technique/technical" does not refer to a "thing" but "a modus operandi, a chain of gestures and know-how, bringing about some anticipated result" (LATOUR, 1994, p. 43). In other words, the author argues that technical mediation is the result of the mobilization of several other actors "blackboxed" in a technical object, and technologies should be included in intellectual culture as complete social actors, because "technical action is a form of delegation that allows us to mobilize, during interactions, moves made elsewhere, earlier, by other actants" (LATOUR, 1994, p. 52), revealing links and associations between various humans and nonhumans.

Consider things and you will have humans. Consider humans, and you are by that very act interested in things. Bring your attention to bear on hard things, and see them become gentle, soft or human. Turn your attention to humans, and see them become electric circuits, automatic gears or software. (LATOUR, 2000, p. 20).

Thus, many of the elements that we consider part of a "social order" - such as scalability, asymmetry, durability, power, hierarchy, role distribution - are impossible to define without invoking nonhumans. All this because, for millions of years, humans "have extended their social relations to other actants with which, with whom, they have swapped many properties, and with which, with whom, they form collectives" (LATOUR, 2000, p. 53). Do technical artifacts mediate our actions, then? "No, they are us" (LATOUR, 2000, p. 65), says Latour. We ourselves are the result of various associations. As an example, just look at the dependence of our memory on material objects - from a personal notebook to the smartphone.

Even having pointed out the specificities of the two concepts that we bring to our aid in this work, it is important to emphasize that we are not ignoring the conceptual differences between these two authors. We know how Latour's (1994) view of technical mediation (quite) differs from Winner's (1977) view of autonomous technology. To make this issue clearer, we borrow the words of Furtado (2018, p. 33, free translation):

While the first [Latour] argues that a technical action is the result of the mobilization of various other actants that in the past were blackboxed in an object, for example, the second argues that technical artifacts have a certain autonomy to act and are not under the control of humans. Although both perspectives emphasize the interdependence of humans and technology, Winner (1977) argues that objects 
have a degree of independence, while Latour (1994) emphasizes that action is the result of a "chain of mediations".

Even with these conceptual and philosophical divergences, we believe that it is possible to create an analytical instrument by combining these two important concepts from two important authors in the STS field.

\section{The controversy - control, accountability and guilt}

There were several times when the platform was featured in the media during the two years analyzed. But in our view, the critical point of the controversy was in November 2016, with the blaming (SHONTELL, 2016) - and subsequent confirmation (CONDLIFFE, 2016) - of the influence of false content on the results of the 2016 US presidential election, home country of the platform. It seems to us that it was at this moment that the consequences of the actions of the elements that compose the platform were scaled up and could be better understood by the public. For example, the way selection algorithms on a social networking platform can ultimately influence the results of a presidential election of one of the world's most powerful countries (BUMP, 2018).

The US elections occurred in November, but by May 2016 the platform had already faced charges involving biased selection of news by its algorithms in a controversy involving its "Trending" tool (NUNES, 2016). Trending ${ }^{4}$ (KASTRENAKES, 2018) was designed to provide users in some countries (WAGNER, 2014) $)^{5}$ with a list of topics that "have recently reached the peak in popularity" (STRUHAR, 2014). The links that were "trending" on Facebook were selected algorithmically, based on a set of pre-established criteria not disclosed to the public. Then, the links went through the selection of a team of human employees, trained according to criteria that resembled the classic standards of professional journalism, such as "relevance" and "importance" (THIELMAN, 2016) and, after that, again went through an algorithmic selection to customize content for users.

Criticism at the time referred to the omission of the presence of human employees, in an allegedly mechanic process, and denounced a supposedly biased selection of content favorable to the Democratic presidential candidate Hillary

4 The tool was completely deleted in June 2018.

5 According to this article published on the Mashable website, before the official release, the tool would initially be available in the United States, the United Kingdom, Canada, India and Australia. 
Clinton, which actually included a list of links to "fake news" in a tool for the publication of journalistic content (NUNES, 2016). After being summoned to provide formal explanations by the government, Mark Zuckerberg welcomed twelve Republican Party leaders to the Facebook headquarters in an attempt to reconcile (ZUCKERBERG, 2016a). To control the problem, he dismissed all human employees in the Trending section, in a process in which subjectivity was presented as inherent to human action and, therefore, firing employees and completely delegating the work to algorithms would bring back selection objectivity (WONG et al., 2016).

However, even after facing these problems, Zuckerberg insisted on rejecting the possibility that false content on the platform could influence the election outcome and stated, three days after the election results were released, that "the idea that fake news, which is a very small amount of content, influenced the election anyway is a very crazy idea" (BURKE, 2016), during a technology event. But, as was shown later, misleading content did play a part in Donald Trump's victory and Facebook had to acknowledge its share of the blame (PHILLIPS, 2017). We have seen the company change its speech throughout the controversy from a disqualification of charges to an attempt to regain control of internal processes on the platform, even admitting via executive members that it could not control everything that happens there.

Despite the previous statement, a week later, Mark Zuckerberg published on his personal profile page information about some of the actions being taken to try to combat the dissemination of "fake news". In December 2016, the platform declared war on "Hoaxes and Fake News" (MOSSERI, 2016) and the executive stated that he and his team had "been working on this problem for a long time and we take this responsibility seriously. We've made significant progress, but there is more work to be done" and "we understand how important the issue is for our community and we are committed to getting this right" (ZUCKERBERG, 2016b). This moment was critical in the platform's process of working towards institutionalized journalism with the launch of the Facebook Journalism Project on January 11, 2017 (SIMO, 2017). Throughout 2017, Facebook announced a number of partnerships, changes in News Feed algorithms and initiatives towards institutionalized journalism that orbited around the Facebook Journalism Project. However, it was not until September 2017, after the FBI investigations into the influence of "fake news" in the elections and growing media pressure, that the company began to show signs of admitting a portion of the blame in the process (LEONNIG et al. 2017).

On September 6, 2017, The Washington Post published a story echoing the post made by the company's Chief Security Officer, Alex Stamos, on the Facebook 
blog: "The acknowledgment by Facebook follows months of criticism that the social media company served as a platform for the spread of false information before the November election" (LEONNIG et al. 2017). According to Stamos (2017), when reviewing ad purchases, approximately $\$ 100,000$ in expenses were found between June 2015 and May 2017 - associated with about 3,000 ads - linked to 470 fake accounts and pages that violated the platform's policies. The executive also stated that Facebook deleted accounts that were still active and that "we know we have to stay vigilant to keep ahead of people who try to misuse our platform" (STAMOS, 2017).

On September 21, 2017, Mark Zuckerberg posted on his personal profile: "Now, I wish I could tell you we're going to be able to stop all interference, but that wouldn't be realistic" (ZUCKERBERG, 2017a), in reference to the use of platform tools to "undermine democracy" (ZUCKERBERG, 2017a). This was the first time the company really participated and admitted the platform's influence on the process.

This publication set the tone of the official messages for the following months. In the speeches that followed the acceptance of platform participation in the activities of "bad actors", the company conveyed the idea that it lost control of its processes due to not being aware of the possibility of such uses, but that it would be working to regain this control with new measures and actions.

On September 30, 2017, Zuckerberg (2017b) posted on his personal page an apology "for the ways my work was used to divide people rather than bring us together, I ask forgiveness and I will work to do better". However, it was not until October 2 of the same year - two weeks after the admittance that the ads were used to influence voters and after several requests for greater transparency - that the platform decided (ISAAC; SHANE, 2017) to give internal documents and information on the accounts used to spread the content to government investigators. In Zuckerberg's (2017a) speech, the executive also points out measures to prevent the misuse of ads and algorithms: nine steps being taken to "protect election integrity and make sure that Facebook is a force for good in democracy" (ZUCKERBERG, 2017a).

Throughout the platform's official publications and the measures announced in the coming weeks - such as their plans to hire a thousand human reviewers to ensure that ads align with the terms of the platform (INGRAM, 2017) - it is possible to see how the idea of technical control still permeates the imaginary of this sociotechnical environment and continues to be used as a guide for the elaboration of containment measures for "inappropriate" content.

This demand for control also emerges from the content of institutionalized media outlets. Examples can be seen in some of the headlines listed below, although 
some journalists present arguments that question this idea of control in the text of some of the articles analyzed. The headlines are: "Who will take responsibility for Facebook?" (HEFFERNAN, 2017) and "Facebook can absolutely control its algorithm" from Wired (GRIFFITH, 2017); "Do Facebook and Google have control of their algorithms anymore? A sobering assessment and a warning" from Poynter (KRAMER, 2017); and "Maybe social media is broken" from Bloomberg (O’NEIL, 2017a).

When the "discoveries" about the platform use by "bad actors" ceased, Facebook was the target of another scandal involving the misuse of data of 87 million users. The controversy surrounding Cambridge Analytica began following the publication of a denunciation by The New York Times (ROSENBERG, 2018) and The Guardian (CADWALLADR; GRAHAM-HARRISON, 2018), on March 17, 2018, stating that data from millions of users had been misused to produce information and political strategies influencing not only the US elections, but the outcome of the \#Brexit referendum - in which it was decided for England to leave the European Union. The scandal culminated in Mark Zuckerberg being interrogated for ten hours by US politicians, in the Senate and House of Representatives, in April 2018 (WICHTER, 2018), and by several European Parliament politicians in May of the same year. In Brussels, facing the politicians of the European Union, the executive said:

It has become evident that in recent years we have not done enough to prevent the tools we have built from being misused. Whether it was fake news, foreign interference in elections or misuse of personal data, we did not have a sufficiently comprehensive view of our responsibility. That was a mistake, I'm sorry. (DN, 2018. Underlined by the author)

In the quote above, we see how the idea of "error" and lack of control continues to emerge from the official speeches of the company. And it goes on like this throughout our research.

\section{Where is the problem?}

The mere idea that the algorithms and the platform were not being sufficiently supervised or that they were not properly programmed and, therefore, needed improvements and more dedication from the responsible teams, demonstrates that the illusion of technical control is still present when thinking about possible solutions 
to the problem at hand. The influence and action of users and the algorithms being actually constituted by their actions, for example, are issues not even considered in these solutions. Authors such as Kitchin (2014) argue that algorithms are not just what programmers aim for, but the result of how users deal with them every day, subverting, reinventing and reworking their initial intentions. Moreover, there is a big difference between the uses thought of by the creators of a technical object and the uses given to them by people inserted in specific sociocultural contexts (PINCH; BIJKER, 1993). Therefore, to disregard their action is to overlook an important part of this sociotechnical network.

Although Facebook executives have softened the "control" speech about the platform throughout the controversy, admitting that some situations simply cannot be controlled, most of their speeches reflect and reverberate the demand for control. When the Cambridge Analytica scandal and user data leaks via platform-internal applications exploded, the demand for control and the idea of losing it came back in full force in official speeches. Still, we insist that the idea of control - be it the possibility or the impossibility of it - is per se the problem to be tackled because it distracts attention from the issues that really need to be solved by the company and that even threaten the privacy and security of its users.

In addition, the speeches about the controversy reverberate the idea that algorithms are neutral and objective machines, that their action could be controlled and predetermined by the executives and programmers, and that they were "misused" by the bad actors in question. From the concept of technical mediation (LATOUR, 1994), presented earlier, it is impossible to think about the action of algorithms detached from other actions that happen at the same time, because they are part of a network of actors that act in an interconnected way.

We cannot say that it is the algorithms that are wrong, or that users have used the platform in the wrong way, but that it is the various agencies of various actors that drive the action in a particular way. Algorithms are not only what programmers want, but the result of actions that happen in the network of which they are a part. In fact, most of the problems surrounding the algorithms we have seen in the media in recent years are related to the size of the power delegated to them and the importance of the decisions they have been allowed to make under their own operating logic.

Thus, we can say that it was the various mediations, the various layers of actions involved in the mediation of this technical entity, that generated these various problems. After all, the algorithm itself, as a technical entity, is the result 
of "congealed labor" that brings to the scene several actants distant in time and space (LATOUR, 1994, p. 40).

This simplistic view of technical action also hides the complexity of these algorithms by referring to them as a unit and as if they, as a whole, could be thought of as a unit. How can we say that the algorithm is wrong or is to blame for an action, when "in fact, what we might refer to as an algorithm is often not one algorithm but many" (GILLESPIE, 2014, p. 178)? Moreover, even after "tweaks" and "improvements", the algorithms do not become stable or predictable either. According to Gillespie (2014, p. 178),

[...] while the technology may be "blackboxed" (Latour 1987; Pinch and Bijker 1984) by designers and users alike, that should not lead us to believe that it remains stable. In fact, algorithms can be easily, instantly, radically, and invisibly changed. While major upgrades may happen only on occasion, algorithms are regularly being "tweaked".

For Mike Ananny, when Facebook claims to be a technology company and not a media company, it can allege (based on the widespread idea that technology is neutral) that "any perceived errors in Trending Topics or News Feed products are the result of algorithms that need tweaking, artificial intelligence that needs more training data, or reflections of users" (ANANNY apud BELL; OWEN, 2017). The author thus states that the company disclaims its mediation in the process, a mediation similar to an editorial position. The problem with this action lies in the criteria that are used as the basis for this algorithmic selection.

In a review published in The Wall Street Journal, journalist Christopher Mims warns that "we have barely begun to understand how the massive social network shapes our world" (MIMS, 2017) and that Facebook remains in denial about its main problem:

What the company's leaders seem unable to reckon with is that its troubles are inherent in the design of its flagship social network, which prioritizes thrilling posts and ads over dull ones, and rewards cunning provocateurs over hapless users. No tweak to algorithms or processes can hope to fix a problem that seems enmeshed in the very fabric of Facebook (MIMS, 2017).

When the work of deciding what should be viewed and by whom, what has relevance and what does not, is (mostly) done by algorithms, based on lists 
of criteria that target audience and keeping the user on the platform for longer, problematic issues start to gain visibility and to spread massively across the web such as violence, pedophilia and even "fake news". The problem then is not lack of control over the algorithms, but their operating logic and the magnitude of their decision-making autonomy.

Furthermore, Cathy O'Neil (2017b) draws our attention to the fact that mathematical models, such as Facebook's algorithms, are not objective and carry the subjectivity and bias of their programmers. This is because

[...] our own values and desires influence our choices, from the data we choose to collect to the questions we ask. Models are opinions embedded in mathematics. (...) In each case, we must ask not only who designed the model, but also what that person or company is seeking to achieve. (O'NEIL, 2017b, p. 21)

For that reason, the more open, diverse and inclusive the programming teams of a company like Facebook are, the greater the chance that the resulting algorithms will also be more open, diverse and inclusive. These algorithms are the result of the "blackboxing" of various classification, valuation, categorization and evaluation processes. They were created to automate and reduce the work that had been previously done by many humans over an infinitely longer time frame. There are so many processes and so many algorithms, that the network of agencies on a platform as large as Facebook can no longer be controlled by its creators - at least not completely. According to Zeynep Tufekci (2017),

[...] we no longer really understand how these complex algorithms work. We don't understand how they're doing this categorization. It's giant matrices, thousands of rows and columns, maybe millions of rows and columns, and not the programmers and not anybody who looks at it, even if you have all the data, understands anymore how exactly it's operating.

In such a way, we believe that the idea of autonomy of these actors is linked to this impossibility of a complete knowledge about them. These algorithms conducting platforms, such as Facebook, have become so complex that not even the people behind them can really understand them entirely, contrary to what Zuckerberg and his executives insist on stating in the company's official publications.

Advocating for the autonomy of these technologies does not mean that Facebook executives and programmers should be exempt from responsibility "because 
algorithms could not be controlled," as Erin Griffith (2017) points out. According to the author, Facebook even demonstrates that the company knows very well in which pieces of the network to act to create detours in the desired direction when it is interesting to its market.

Facebook's algorithm is determined by data, and it's based on what users want. Changes to the News Feed algorithm are in the name of getting users increasingly addicted to Facebook. So far, fake news has proven to be addictive; in the last year, Facebook's user base and revenue have grown by $17 \%$ and $47 \%$, respectively (GRIFFITH, 2017).

Although the author demands that the platform take "full responsibility" for what goes around on the platform, which we do not think is possible, we agree when she says that Facebook's influence today is huge and powerful and "the responsibility that comes with it is a work in progress" (GRIFFITH, 2017). We believe full responsibility is not possible because we cannot completely predict and control the action of the algorithms and the thousands of people who are getting in contact with and transforming them every day.

The "fault", then, is neither Mark Zuckerberg's as a person, who "lost control" of his platform, nor of a particular algorithm or group of algorithms wrongfully programmed. Zuckerberg may be legally responsible for his company's actions because he is the CEO, but that does not solve the problem and continues to perpetuate a lack of knowledge of the actual operation of Facebook and other similar platforms.

The problem lies in the very logic of operation that is intrinsic to those algorithms that have a deterministic, simplistic and mechanic logic, incompatible with the complexity of the human actions which they are increasingly responsible for controlling and organizing. The problem is also in the selection and operation criteria that underlie these algorithms and serve as the basis for determining what will have visibility on the platform. Although they affect a multitude of actors, they are not open to the public or to expert auditors, not even to academic researchers. ${ }^{6}$ And an even bigger problem is the degree of autonomy and power these agents have gained in such large and meaningful sociotechnical networks of circulation of information such as Facebook.

Bucher (apud D'ANDRÉA; JURNO, 2018) warns that the focus on the search for this accountability of algorithmic actions causes us to deviate from the 6 As is Twitter. See Gadde and Roth (2018). 
question that should really matter: when these actions occur and how to stop them from happening again. Because, says Frank Pasquale (2015, p. 14), "the power to include, exclude, and rank is the power to ensure that certain public impressions become permanent, while others remain fleeting".

Therefore, the more open to public scrutiny networks are - whether through the action of specialized auditors prepared to detect potential problems, the diversification of teams, a broader discussion about the criteria and values that underlie their actions, or through the openness to the analysis of their influence by academic researchers - the more adaptable and malleable they can be. If the action is divided into the network of actors, the actors themselves should then be able to know and access this network more freely, even with the constraints that a capitalist business model requires.

\section{Final notes}

In this paper, we argue that the illusion of technical control focuses on attempts to curb platform problems and "misuse", in an effort to create technical barriers to control what users are doing inside the platform, ensuring that everything works correctly there. This would only be possible if we disregard that sociotechnical networks are in continuous motion. Algorithms and platforms are not just what programmers and developers want, but the result of how users deal with them on a daily basis. We believe that the focus of the efforts should be trying to understand these networks and work with the agencies there to avoid drastic consequences, such as those pointed out throughout the controversy. The search for this control only generates anguish and postponement of the real issue that should be to prevent these actions from reoccurring, putting at risk the various actors that are part of this network.

In addition, the idea that technologies and technical entities are neutral, stable and objective helps in the process of perpetuating this problem. As journalist Melody Kramer warns, "algorithms can be gamed, algorithms can be trained on biased information, and algorithms can shield platforms from blame" (KRAMER, 2017). The algorithms act and influence the other actants of the networks of which they are a part. Admitting the action of the nonhuman entities that compose this gigantic sociotechnical network is the first step in starting to analyze and trying to understand them, and then think of the best way to live with them. 
According to Bruno Latour (1994), we cannot think about the action of the actors separately. Therefore, it is not possible to think of the action of algorithms independently from the actions of users, executives and the various other actors involved in this process. This is because "the action is a property of associated entities" (LATOUR, 1994, p. 35), and therefore the "responsibility for action must be shared among the various actants" (LATOUR, 1994, p. 34). The difficulty in measuring the role of the mediation of these algorithms lies in their opacity, the difficulty of observation caused by their "blackboxing" and the constant denial of uncertainty involved in this agency.

On the other hand, this "blackboxing" of action programs allows the displacement of the actants in space and time and a detour in the sequence of actions in another network. Humans - executives, users and programmers - are part of some of the layers of mediation involved in the processes that take place on the platform. Each technical entity is the result of "congealed labor" (LATOUR, 1994, p. 40), and it is thus possible to find hundreds, even thousands, of missing creators - remote in time and space - and simultaneously active and present in the network. As a result, the political order is subverted through these detours, because we constantly "rely on many delegated actions that themselves make me do things on behalf of others who are no longer here and that I have not elected and the course of whose existence I cannot even retrace" (LATOUR, 1994, p. 40).

In this paper, we also argue that Facebook can be considered as an autonomous technology in the sense of "a general label for all conceptions and observations to the effect that technology is somehow out of control by human agency" (WINNER, 1977, p. 16). Amid its algorithms, software, processes and users, Facebook has become a highly complex technology over which full control is completely impossible. However, it is necessary to try to understand it to better deal with its actions and to avoid undesirable consequences. The more transparent the company is about its ways of operation and the criteria ruling the action of its algorithms, the easier it will be to understand its role, influence and action in society.

What can be considered our contribution with this paper, then? Since it is not possible to completely control Facebook's algorithms or be aware of all the mediations at stake in each process, should we forget about this and accept the (negative) influence of the platform in our daily lives?

No. Facebook should be held responsible for actions taken under its name. However, this only solves this specific problem and does nothing to prevent future consequences. Therefore, we believe that it is not enough to demand an answer 
exclusively from Facebook, as if the responsibility should not be shared between all the actors of the sociotechnical network. We should demand more transparency and explanations about the actions and the criteria behind those actions. But also, all of us - lawmakers, rulers, executives, programmers and users - are part of this network that generated the "fake news" controversy. We believe that, to fix these issues and work to avoid future problems, we need to act together; for example, by creating clear rules of digital behavior, laws on responsibility for action on platforms and even developing media literacy on this new scenario that many users still do not fully understand. The European Union has been an example of effort along these lines in discussing and proposing regulations for the use of platforms.

Thus, we must distribute the responsibility to the actors who are part of the network and act by offering translations, deviations, detours as Latour (1994) would say, to transform the actions on the platform and guide them on the jointly decided path. But for this to be successful, it is necessary that the work is constant, since the network is alive and the actors are always moving and in constant mediation, translation and transformation.

Therefore, you cannot control Facebook or predict all of its actions, but you can guide them in the direction that is most interesting, based on the knowledge and understanding of those actions.

\section{References}

ANGWIN, Julia; GRASSEGGER, Hannes. Facebook's secret censorship rules protect white men from hate speech but not black children. ProPublica. Jun. 28, 2017. Available at: $<$ https://www.propublica.org/article/facebook-hate-speech-censorship-internal-documentsalgorithms>. Access on: Aug. 05, 2019.

BELL, Emilly; OWEN, Taylor. The platform press: how Silicon Valley reengineered journalism. Tow Center for Digital Journalism. Mar. 29, 2017. Available on: <https://www. cjr.org/tow_center_reports/platform-press-how-silicon-valley-reengineered-journalism.php>. Access on: Aug. 22, 2018.

BUMP, Phillip. All the ways Trump's campaign was aided by Facebook, ranked by importance. Washington Post. 22 Mar. 2018. Available on: <https://www.washingtonpost.com/news/ politics/wp/2018/03/22/all-the-ways-trumps-campaign-was-aided-by-facebook-ranked-byimportance/?utm_term=.b99bc340aaf5>. Access on: Aug. 05, 2019. 
CADWALLADR, Carole; GRAHAM-HARRISON, Emma. Revealed: 50 million Facebook profiles harvested for Cambridge Analytica in major data breach. The Guardian. Mar. 17, 2018. Available at: <https://www.theguardian.com/news/2018/mar/17/cambridge-analyticafacebook-influence-us-election>. Access on: Aug. 05, 2019.

CONDLIFFE, Jamie. Regardless of its influence on the election, Facebook needs to change. Technology Review. Nov 14, 2016. Available at: <https://www.technologyreview. $\mathrm{com} / \mathrm{s} / 602851 /$ regardless-of-its-influence-on-the-election-facebook-needs-to-change/>. Access on: Aug. 05, 2019.

D’ANDRÉA, Carlos; JURNO, Amanda. Algoritmos como um devir: uma entrevista com Taina Bucher. Parágrafo, São Paulo, v. 6, n. 1, p. 165-170, jan./abr. 2018

BURKE, Samuel. Zuckerberg: Facebook will develop tools to fight fake news. CNN. Nov. 19, 2016. Available on: <https://money.cnn.com/2016/11/19/technology/mark-zuckerbergfacebook-fake-news-election/index.html>. Access on: Aug. 22, 2018.

DN - DIÁRIO DE NOTÍCIAS. Zuckerberg no Parlamento Europeu: "Foi um erro, peço desculpa". 22 maio 2018. Available on: <https://www.dn.pt/mundo/interior/fundador-dofacebook-pede-desculpa-a-ue-9366672.html>. Access on: Jul. 25, 2018.

FURTADO, Silvia de Freitas Dal Ben. Cartografando o jornalismo automatizado: redes sociotécnicas e incertezas na redação de notícias por "robôs". 2018. 116 f. -Dissertação (Mestrado) - Universidade Federal de Minas Gerais, Belo Horizonte, 2018.

GADDE, Vijaya; ROTH, Yoel. Enabling further research of information operations on Twitter. Twitter. Oct. 17, 2018. Available at: <https://blog.twitter.com/en_us/topics/ company/2018/enabling-further-research-of-information-operations-on-twitter.html>. Access on: Aug 05, 2019.

GILLESPIE, Tarleton. The relevance of algorithms. In: GILLESPIE, Tarleton; BOCZKOWSKI, Pablo J.; FOOT, Kirsten A. (ed.). Media technologies: essays on communication, materiality, and society. Cambridge, MA: MIT Press, 2014. p. 167-194.

GILLESPIE, Tarleton; BOCZKOWSKI, Pablo J.; FOOT, Kirsten A. (ed.). Media technologies: essays on communication, materiality, and society. Cambridge, MA: MIT Press, 2014.

GRIFFITH, Erin. Facebook can absolutely control its algorithm. Wired. Sep. 26, 2017. Available on: <https://www.wired.com/story/facebook-can-absolutely-control-its-algorithm/>. Access on: Oct. 02, 2017.

HEFFERNAN, Virginia. Who will take responsibility for Facebook? Wired. Oct. 02, 2017. Available on: <https://www.wired.com/story/mark-zuckerberg-who-will-take-responsibilityfor-facebook-now>. Access on: Oct. 02, 2017. 
INGRAM, David. Facebook to hire 1,000 people to review ads after Russian buys. Reuters. Oct 02, 2017. Available at: <https://www.reuters.com/article/facebook-advertising/facebookto-hire-1000-people-to-review-ads-after-russian-buys-idUSL2N1MD03F>. Access on: Oct. 02, 2017.

ISAAC, Mike; SHANE, Scott. Facebook to deliver 3,000 Russia-Linked ads to Congress on monday. The New York Time. Oct. 1, 2017. Available at: <https://www.nytimes. com/2017/10/01/technology/facebook-russia-ads.html>. Access on: Aug. 05, 2019.

KASTRENAKES, Jacob. Facebook will remove the Trending topics section next week. The Verge. Jun 1, 2018. Available at: <https://www.theverge.com/2018/6/1/17417428/facebooktrending-topics-being-removed>. Access on: Aug. 05, 2019.

KITCHIN, Rob. Thinking critically about algorithms. The Programmable City, 2014. (Working Paper, 5).

KRAMER, Melody. Do Facebook and Google have control of their algorithms anymore? Poynter. Nov. 14, 2017. Available on: <https://www.poynter.org/news/do-facebook-andgoogle-have-control-their-algorithms-anymore-sobering-assessment-and-warning $>$. Access on: Jul. 31, 2018.

LATOUR, Bruno. On technical mediation. Common Knowledge, v. 3, n. 2, p. 29-64, 1994.

LATOUR, Bruno. Reassembling the social: an introduction to Actor-Network Theory. Oxford: Oxford University Press, 2005.

LATOUR, Bruno. The Berlin key or how to do words with things. In: GRAVES-BROWN, Paul (ed.). Matter, materiality and modern culture. London: Routledge, 2000. p. 10-21.

LATOUR, Bruno. Where are the missing masses? Sociology of a few mundane artifacts. In: BIJKER, Wiebe E.; LAW, John (ed.). Shaping technology / building society: studies in sociotechnical change. Cambridge: MIT Press, 1992.

LEONNIG, Carol D. et al. Russian firm tied to pro-Kremlin propaganda advertised on Facebook during election. The Washington Post. Sep. 6, 2017. Available on: <https:// www.washingtonpost.com/politics/facebook-says-it-sold-political-ads-to-russian-companyduring-2016-election/2017/09/06/32f01fd2-931e-11e7-89fa-bb822a46da5b_story. html?noredirect=on\&utm_term=.e839141325db>. Access on: Aug. 22, 2018.

LEVIN, Sam. Facebook allowed advertisers to target 'Jew haters'. The Guardian. Sep. 15, 2017. Available at: <https:/www.theguardian.com/technology/2017/sep/14/facebookadvertising-jew-hater-antisemitism>. Access on: Jul. 26, 2019.

MIMS, Christopher. Facebook is still in denial about its biggest problem. The Wall Street Journal. Oct. 1, 2017. Available on: <https:/www.wsj.com/articles/facebook-is-still-in-denialabout-its-biggest-problem-1506855607>. Access on: Jul. 31, 2018. 
MOSSERI, Adam. Addressing hoaxes and fake news. Newsroom. Dec. 15, 2016. Available at: <https://newsroom.fb.com/news/2016/12/news-feed-fyi-addressing-hoaxes-and-fakenews/>. Access on: Feb. 09, 2019.

NEWSROOM. Site. Newsroom. Available at: <https://newsroom.fb.com>. Access on: Jul. 26, 2019.

NUNES, Michael. Former Facebook workers: we routinely suppressed conservative news. Gizmodo. May. 09, 2016. Available on: <https://gizmodo.com/former-facebook-workerswe-routinely-suppressed-conser-1775461006>. Access on: Aug. 05, 2019.

O’NEIL, Cathy. Maybe Facebook is broken. Bloomberg. Nov. 7, 2017a. Available at: <https:/www.bloomberg.com/view/articles/2017-11-07/maybe-social-media-is-broken>. Access on: Aug. 05, 2019.

O'NEIL, Cathy. Weapons of math destruction: How big data increases inequality and threatens democracy. New York: Broadway Books, 2017b.

PASQUALE, Frank. The black box society. Cambridge, MA: Harvard University Press, 2015. PINCH, Trevor J.; BIJKER, Wiebe E. The social construction of facts and artefacts: or how the sociology of science and the sociology of technology might benefit each other. In: BIJKER, Wiebe E. et al. The social construction of technological systems: New directions in the sociology and history of technology. 4. ed. Cambridge, MA: MIT Press, 1993, p. 17-50. PHILLIPS, Kristine. Mark Zuckerberg apologizes 'for the ways my work was used to divide people'. The Washington Post. Oct. 1, 2017. Available at: <https://www.washingtonpost. com/news/the-intersect/wp/2017/10/01/mark-zuckerberg-apologizes-for-the-ways-my-workwas-used-to-divide-people/>. Access on: Aug. 05, 2019.

ROSENBERG, Matthew et al. How Trump consultants exploited the Facebook data of millions. The New York Times. Mar. 17, 2018. Available at: <https://www.nytimes. com/2018/03/17/us/politics/cambridge-analytica-trump-campaign.html>. Access on: Aug. 05, 2019.

SHONTELL, Alyson. Facebook is being blamed for Trump's election - but Mark Zuckerberg's response is tone deaf. Business Insider. Nov 11, 2016. Available at: <https:// www.businessinsider.com/facebook-blamed-trump-election-mark-zuckerberg-response-tonedeaf-2016-11>. Access on: Aug. 05, 2019.

SIMO, Fidji. Announcing the Facebook journalism project. Newsroom. Jan. 11, 2017. Available at: <https://newsroom.fb.com/news/2017/01/announcing-the-facebook-journalismproject/>. Access on: Feb. 09, 2019. 
STAMOS, Alex. An update on information operations on Facebook. Newsroom. Sep. 06, 2017. Available on: <https://newsroom.fb.com/news/2017/09/information-operationsupdate/>. Access on: Oct. 02, 2017.

STRUHAR, Chris. Finding popular conversations on Facebook. Newsroom. Jan. 16, 2014. Available on: <https://newsroom.fb.com/news/2014/01/finding-popular-conversations-onfacebook/>. Access on: Feb. 09, 2019.

THIELMAN, Sam. Facebook news selection is in hands of editors not algorithms, documents show. The Guardian. May 12, 2016. Available at: <https:/www.theguardian.com/ technology/2016/may/12/facebook-trending-news-leaked-documents-editor-guidelines>. Access on: Feb. 09, 2019.

TUFEKCI, Zeynep. We're building a dystopia just to make people click on ads. TED - Ideas worth spreading. Sep., 2017. Available on: <https://www.ted.com/talks/zeynep_tufekci_we_ re_building_a_dystopia_just_to_make_people_click_on_ads/transcript\#t-9834>. Access on: Jul. 31, 2018.

VENTURINI, Tommaso. Diving in magma: how to explore controversies with actor-network theory. Public Understanding of Science, v. 19, n. 3, p. 258-273, 2010.

WAGNER, Kurt. Facebook will now tell you what's most popular on Facebook. Mashable. Jan. 16, 2014. Available at: <https://mashable.com/2014/01/16/facebooktrending/\#4aEiQ2Iggiqw>. Access on: Aug. 05, 2019.

WICHTER, Zach. 2 days, 10 hours, 600 questions: what happened when Mark Zuckerberg went to Washington. The New York Times. Apr. 12, 2018. Available at: <https://www.nytimes. com/2018/04/12/technology/mark-zuckerberg-testimony.html>. Access on: Aug. 05, 2019.

WINNER, Langdon. Autonomous technology: technics-out-of-control as a theme in political thought. Cambridge, MA: MIT Press, 1977.

WINNER, Langdon. Technologies as forms of life. Epistemology, methodology, and the social sciences. Springer Netherlands, 1983. p. 249-263.

WINNER, Langdon. Upon opening the black box and finding it empty: social constructivism and the philosophy of technology. Science, Technology, \& Human Values, v. 18, n. 3, p. 362-378, 1993.

WONG, Joon Ian et al. Facebook is trying to get rid of bias in Trending news by getting rid of humans. Quartz. Aug. 26, 2016. Available on: <https://qz.com/768122/facebook-fires-human-editors-moves-to-algorithm-for-trending-topics/>. Accessed on: Feb. 09, 2019. ZUCKERBERG, Mark. Photo. Facebook. May 18, 2016a. Available on: <https://www. facebook.com/photo.php?fbid=10102840575485751\&set=a.529237706231.2034669.4\& type $=3 \&$ theater $>$. Accessed on: Jul. 11, 2016. 
ZUCKERBERG, Mark. Post. Facebook. Nov. 19, 2016b. Available on: <https://www. facebook.com/zuck/posts/10103269806149061>. Access on: Aug. 22, 2018.

ZUCKERBERG, Mark. Post. Facebook. Sep. 21, 2017a. Available on: <https://www.facebook.com/zuck/posts/10104052907253171>. Access on: Oct. 02, 2017.

ZUCKERBERG, Mark. Post. Facebook. Sep. 30, 2017b. Available on: <https://www.facebook.com/zuck/posts/10104074437830721>. Access on: Oct. 02, 2017.

\section{(cc) EY-NC}

Esta obra foi licenciada sob uma Licença Creative Commons Atribuição-NãoComercial 3.0 Brasil. 